\title{
O espaço-tempo da EAD: caminhos de experienciação
}

\author{
Joyce Munarski Pernigotti* \\ Claudia Cisiane Benetti** \\ Marcio Fenili Antunes ${ }^{* * *}$ \\ Mara Lucia Salazar Machado ${ }^{* * *}$ \\ Edison Luiz Saturnino ${ }^{* * * *}$ \\ Luis Soledade Silva $a^{* * * * *}$
}

Resumo: O presente artigo trata do processo de constituição de uma equipe multidisciplinar para instauração de proposta educativa para Educação a Distância (EAD) em uma Instituição de Ensino Superior brasileira da rede privada. A construção de premissas para fundamentar a operação pedagógica é tematizada a partir de modos de existir que se nutrem pelos conceitos de encontro, afetos e afetações, evidenciando os entendimentos que se criaram a partir da intensa interação dos membros da equipe. Enfatiza-se que o produto desse processo é decorrente

* Professora da Faculdade Cenecista de Osório, RS. Doutora em Psicologia (PUCRS). Coordenadora do CEAD/CNEC. E-mail: joycemp@terra.com.br

** Professora da Faculdade Cenecista de Osório, RS. Doutora em Educação (UFRGS). Membro da equipe multidisciplinar do CEAD/CNEC. E-mail: cisiane@terra.com. br

*** Professor da Faculdade Cenecista de Osório, RS. Mestre em Geografia (UFRGS). Membro da equipe multidisciplinar do CEAD/CNEC. E-mail: geografia@facos. edu.br

**** Professora da Faculdade Cenecista de Osório, RS. Mestre em Educação. Membro da equipe multidisciplinar do CEAD/CNEC. E-mail: mara.machado@terra.com.br

***** Professor da Faculdade Cenecista de Osório/RS. Doutor em Educação (UFRGS). Membro da equipe multidisciplinar do CEAD/CNEC. E-mail: edisonsaturnino@ terra.com.br

${ }^{* * * * * *}$ Licenciado em Computação. Membro da equipe multidisciplinar do CEAD/CNEC. E-mail: luissoledade@ig.com.br 
de escolhas que configuram os conceitos que são fios condutores da proposta educativa da EAD, tais como: ética, problematização e cooperação.

Palavras-chave: Equipe multidisciplinar; Encontros; Afetações; Problematização; Etica.

Abstract: This article studies the constitution process of a multidisciplinary team in order to develop an educational proposition for a Distance Education program in a Brazilian private University. The premises built in order to base the pedagogical operation are treated based in ways of 'being' that are fed by conceptions of 'meeting', 'affection' and 'to affect', putting in evidence the understanding created from the intense interaction among the components of the team. It is stressed that the product from this process is fruit of the choices that set the concepts that are the conducting wires of the educational proposition of the Distance Education, such as: ethics, problematization and cooperation.

Keywords: Multidisciplinary team; Meetings; To affect; Problematization; Ethics.

\section{O Cenário}

A Campanha Nacional de Escolas da Comunidade (CNEC), fundada em 1943, é uma rede educacional cuja identidade e missão preconizam a dedicação à Educação e serviços afins, promovendo a formação integral das pessoas, por meio de uma educação de qualidade, com compromisso social. A Instituição fundamenta suas crenças e seus valores nos princípios éticos, na valorização do ser humano, competência e no compromisso na oferta de serviços e produtos educacionais de excelência. Atualmente, a CNEC atua no Ensino Superior em dez estados brasileiros e no Distrito Federal com vinte e quatro faculdades que ofertam cento e vinte e oito cursos de graduação. A maioria das unidades cenecistas está localizada em municípios distantes dos grandes centros e nos quais a oferta educativa é escassa. $\mathrm{O}$ âmbito 
de sua atuação abrange, além da Educação Superior, os níveis Infantil, Fundamental, Médio, Profissional e Jovens e Adultos.

Em 2010, a CNEC optou por ofertar Educação a Distância na Educação Superior. Para tanto, escolheu a Faculdade Cenecista de Osório como instituição responsável por criar e abrigar um Centro de Educação a Distância (CEAD/CNEC), a quem compete a coordenação das ações em Educação a Distância da CNEC, a ser efetivada através de trinta e oito polos localizados em unidades da rede CNEC, em quinze estados brasileiros.

O trabalho está centrado em uma equipe multidisciplinar, composta por profissionais de diferentes formaçôes, a saber, educação, tecnologia, administração, cujas atribuiçôes são de criação, operacionalização, monitoramento e aperfeiçoamento permanente da proposta educativa. A essa equipe coube a tarefa de equacionar a proposta na modalidade, desenhando arquiteturas e topologias adequadas, a fim de oferecer educação de qualidade, considerando a fundamentação legal, as realidades das populações a serem atendidas e as especificidades dos cursos, tanto no que diz respeito a diretrizes curriculares quanto aos procedimentos didático pedagógicos.

No presente artigo, apresentamos fragmentos desse processo, intencionando dar visibilidade a um modo de produzir conhecimento que se vale da aliança com conceitos de autores como Foucault, Deleuze e Guattari.

\section{A constituição da proposta educativa: Pensar, mas como? Conhecer, mas como? Aprender, mas como? Ensinar, mas como? Viver, mas como?}

$\mathrm{O}$ "como" talvez seja o termo mais recorrente diante de desafios e incertezas, nesse caso, a criação de um novo espaço educativo. Essa questão potencializa-se quando se trata da 
inserção de uma variável tão relevante quanto uma operação de Educação a Distância.

Um ponto de partida é problematizar a própria noção de distância, pois estar distante em um processo educativo não depende de posição espacial. Podemos estar distantes em uma sala de aula presencial, mesmo quando estamos de corpo presente, compartilhando um mesmo espaço físico. Afinal, não será a distância um operador sempre presente nos processos educacionais, nas relações humanas, como algo a eles imanente? Acredita-se que o pertencimento de sujeitos a uma proposta educativa em EAD depende essencialmente do grau de afetação que tal proposta possa neles produzir

A noção de distância é um operador que se constitui e está instituído em qualquer relação, geralmente assumida em uma dimensão topológica, espacial, geográfica, enfim. Acreditamos, ao atuar no âmbito da EAD, que a relação que se estabelece não diz respeito só a uma relação de espaço, pois envolve o tempo e, nesse sentido, trabalhamos o tempo como um exercício de proximidade, como a busca de condições nas quais a dimensão à distância é torcida e tensionada (PERNIGOTTI, 2004). Pensamos com isso que a dimensão à distância requer um tempo que está para além do tempo cronológico, privilegiando, assim, o tempo da intensidade que se constitui por afetações. Nesse sentido, a problematização da concepção "a distância” envolve muito mais do que tratar de aspectos físicos, pois envolve processos de afetações que caracterizam relações em EAD.

Com esse pressuposto, o processo de corporificação do Centro de Educação a Distância (CEAD CNEC) fez com que a equipe multidisciplinar, ao se deparar com múltiplos desafios, propusesse a construção coletiva desse espaço educativo em uma instituição ancorada no ensino presencial, tendo presente que a tarefa não estava relacionada à mera transposição de práticas já conhecidas diretamente ao novo suporte. Daí a importância de se pensar, por um lado, na perspectiva da desnaturalização de modos já instituídos de ser e agir e, por outro, nas características 
e especificidades do suporte tecnológico de maneira a propiciar uma formação qualificada. Esse interjogo de pensamento foi e é a aposta da equipe na construção do CEAD/CNEC.

Promover aventuras de pensamento e propagar modos de pensar que produzissem rupturas à reprodução e repetição do mesmo implicou um movimento interno de construção e reconstrução da equipe multidisciplinar, que se vale de perspectivas de diferentes áreas de saber e, portanto, diferentes posições epistemológicas. Ou seja, foi necessário romper com um modo de pensar e atuar pautado pela individualidade, procurando avançar na construção de maneiras de se trabalhar, produzir e pensar coletivamente. Tarefa complexa, mesmo em uma instituição educativa.

Acolhimento e incitação de potências de cada integrante da equipe a partir de sua formação instauram modos de ser no grupo que exigem constante repensar, refazer, reaprender no coletivo. Esse movimento interno se caracteriza por experienciações de outros modos de agir, pensar e ser, diferentes dos que estamos habituados, o que imprime uma concepção de trabalho coletivo pautado não em verdades absolutas e inquestionáveis, mas pelo aprender a interagir de forma responsável com as diferentes perspectivas e os sentidos atribuídos à realidade pelos sujeitos. Entende-se com Nietzsche (1945, p. 84) que "[...] conformar-se com o que se é, pode ser um anseio de granito, nunca de homem. Buscar ser mais do que se é, para um além de si mesmo não é uma afronta ao homem. É realizar-se”.

Dessa maneira, é oportuno reafirmar que a construção do espaço-tempo de EAD na CNEC constitui-se pela perspectiva do acolhimento dos diferentes modos de pensar, problematizando a proposta educativa em suas bases filosóficas, epistemológicas e metodológicas. Uma vez exaustivamente debatidas, as posições dos sujeitos constituem premissas da edificação do projeto, a partir de conceitos que atravessam as ações propostas. Esses conceitos estão a seguir explicitados. 


\section{Conceitos da operação pedagógica}

Para dar conta da proposição de um modo de existir em EAD construído por problematizações, afetações, experienciações em consonância com os princípios da IES, a equipe multidisciplinar direciona suas ações de forma implicada com a busca de uma formação fundamentada na ética aliada à problematização como posicionamento filosófico/pedagógico, que se consubstancia em práticas que expressam interatividade, cooperação, autonomia e hipertextualidade. Estas constituem-se em fios condutores das relações entre professores, equipes dos cursos e deles com seus alunos, na ancoragem da operação pedagógica. Assim, o intento está em construir um " [...] lugar de pensamento em que coexistam os diferentes tipos subjetivos, dados nas verdades singulares de seu tempo" (BADIOU, 1995, p. 38).

Figura 1: Conceitos da operação pedagógica CEAD/CNEC

\section{Ética e Problematização}

Hipertextualidade Interatividade Cooperação Autonomia 
Entende-se, assim como Marcondes (2007), que um dos sentidos atribuídos à ética diz respeito a nossa experiência cotidiana, levando-nos a uma reflexão sobre os valores que adotamos e que também nos produzem, sobre os sentidos dos atos que praticamos e a maneira pela qual tomamos decisões e assumimos responsabilidades em nossas vidas.

Considera-se que na produção das subjetividades ou na produção social da existência é de fundamental importância que se estabeleça a ética como princípio orientador do trabalho. Com isso, instala-se a demanda de que os desencadeadores do processo pedagógico possam criar modos de pensar e se responsabilizar com as diferentes e heterogêneas manifestações sócio-culturais constituintes da contemporaneidade. Dito de outro modo, o posicionamento ético implica responsabilizar-se com modos diferentes de existir, o que exige sensibilidade, produção de encontros, acolhimento e acionamento das potências de cada um e de todos nos processos de aprendizagens.

É o comprometimento ético um elemento direcionador das práticas educacionais que visam à constituição de valores voltados ao encontro e à acolbida (LEVINAS apud CARBONARA, 2008). Nessa perspectiva, as ações dão-se em favor da vida, da alteridade e do reconhecimento do outro. De acordo com Carbonara (2008, p. 134):

A educação - espaço de construção do humano - acontece à medida que a responsabilidade pelo Outro é o mote de toda a ação formativa. Educação ocorre sempre que há um encontro humano, em que a abertura ao Outro sobrepõe-se ao interesse do Mesmo, sempre que a escuta antecede a pronúncia, sempre que o esforço da relação se dá em favor da vida.

$\mathrm{Na} \mathrm{EAD}$, talvez até mais intensamente do que na relação presencial, o acolhimento, cuidado de si e do outro e promoção de bons encontros em todas as relações que se estabelecem nas ações pedagógicas formativas, são essenciais para o pertencimento do aluno ao curso, mas também é a âncora que mantém a equipe atuando em sintonia. Compreende-se que tais ações ocorrem em um processo aberto que está em constante reavaliação e ressignificação dos 
componentes que a integram. Parte-se da premissa de que o ser humano é incompleto e em permanente formação, que produz e vivencia as mudanças históricas, culturais, sociais e políticas, podendo construir, através do processo formativo, modos de ser e de agir solidários e interativos que lhe possibilitam alcançar o estatuto de cidadania. De acordo com Cenci, Dalbosco e Fávero (2008, p. 119) um "[...] profissional sem abertura para o mundo, sem sensibilidade moral, estética e social não possui estatuto pleno de cidadania”.

A abertura para o mundo é relevante nos processos formativos, uma vez que possibilita vivências solidárias pautadas pelas diferenças, pelo convívio com o outro, sempre implicados com a responsabilidade sobre nosso fazer. Entende-se que por mais simples que seja nossa atividade, este nosso fazer está sempre produzindo desdobramentos, dobras, redobras e sobredobras. Daí a compreensão de que

[...] a alteridade infinita é simplesmente $o$ que há. Qualquer experiência é desdobramento ao infinito de diferenças infinitas. Mesmo a pretensa reflexão infinita de mim mesmo, ela não é em absoluto a intuição de uma unidade, mas um labirinto de diferenciações (BADIOU, 1995, p. 50).

Essas diferenciações estão presentes nos processos pedagógicos em EAD, uma vez que na experimentação e utilização das tecnologias de informação e comunicação em rede manifestamse múltiplos modos de ser, pensar e habitar os ambientes com posições e ações também múltiplas, que demandam constantes reflexões do ponto de vista ético e pedagógico.

Há que se considerar que os posicionamentos éticos precisam interagir também com as questões formativas que constituem os processos de ensino e aprendizagem. Isso quer dizer que a responsabilidade com os diferentes modos de existir, a promoção dos bons encontros e o cuidado mútuo necessitam estar fortemente associados aos universos discursivos de cada curso de graduação, num movimento em que se tenha clareza do que ensinar, do como ensinar, do que não ensinar, do que não se pode deixar de ensinar, tendo em vista as vivências cotidianas e a futura atuação 
profissional dos egressos dos cursos de EAD CNEC. Tomemos como exemplo o caso das Licenciaturas, nas quais o foco de preocupação não pode ser somente a pertinência do ensino que se oferece a acadêmicos, mas, antes de tudo, a relevância do ensino que os egressos poderão oferecer aos seus alunos, quando estiverem atuando como professores da escola básica.

Aliado ao princípio ético, torna-se fundamental imprimir um modo de pensar, no processo de formação em EAD, que provoque rupturas às soluções unitárias e homogeneizantes dos problemas que emergem no mundo da vida. Nesse sentido, reforça-se o entendimento do conhecimento como construído na interação entre o sujeito e a cultura, sendo importante pensar a forma como os estudantes do ensino superior estão construindo competências que lhes possibilitem interagir no espaço de sua profissão, com o entendimento de que nada pode substituir a atuação do próprio aluno na tarefa de construir significados sobre os conteúdos da aprendizagem.

Mas como promover uma consistente interação entre os sentidos que podem ser atribuídos aos conteúdos da aprendizagem e os sentidos da própria vida dos acadêmicos? Por certo que produzir significados para o que se aprende encontra-se intimamente relacionado com o olhar que lançamos sobre o mundo, com a maneira que problematizamos este mundo e com as possibilidades de estranhamento da vida cotidiana. Nessa perspectiva, o ato de problematizar não acontece separado do modo como nos constituímos no âmbito da cultura, naquilo que nos perturba e provoca em nós o desassossego, deflagrando então processos reflexivos que nos fazem pensar alternativas àquilo que nos inquieta.

Nas definições de dicionário, problematizar significa tornar problemático, dar forma de problema. Problema significa questão que se propóe para ser resolvida. No vocabulário filosófico, a palavra 'problema' "[... ] refere-se a uma situação que não tem um significado único ou que inclui alternativas de qualquer espécie” (ABBGNANO, 1982, p. 764). 
Filosoficamente, o exercício de perguntar corresponde a um processo de abertura de horizontes de sentido, no qual a procura pela pergunta mais apropriada é mais importante que o próprio ato de responder adequadamente. A pergunta coloca em movimento novas possibilidades interpretativas, que desnaturalizam certezas e respostas prontas, e essa foi a aposta que permeou o trabalho da equipe multidisciplinar do CEAD CNEC, a saber, colocar em pauta perguntas que movimentem possibilidades interpretativas e açóes diferenciadas. Conforme Foucault (1994), é preciso perguntar-se por que dessa maneira e não de outra que tais acontecimentos e verdades se instituem?

Para que se produzam significados e se construa conhecimento faz-se necessário compor a problematização da realidade como um modo de operação cognitiva e afetiva constante, que requer o enfrentamento do desconhecido na busca da solução ao que nos fez pensar. Nesse processo se entende que "[...] pensar é experimentar o incômodo do desconhecido, do ainda - não pensado e construir algo que nos possibilite enfrentar o problema que nos fez pensar" (GALLO, 2008, p. 118). É necessário que as situações da realidade possam desassossegar/afetar o sujeito e arremessálo em um movimento de pensamento. A partir deste incômodo inicial, há o desencadeamento cognitivo acompanhado de outro (professor, orientador, colega) que possibilita o desdobramento de possíveis soluções e aprendizagens.

A aprendizagem não é solitária e, conforme Deleuze,

[...] nada aprendemos com aquele que nos diz: faça como eu. Nossos únicos mestres são aqueles que nos dizem 'faça comigo' e que, em vez de nos propor gestos a serem reproduzidos, sabem emitir signos a serem desenvolvidos no heterogêneo (1988, p. 54).

O conceito de aprendizagem é tributário da atividade do pensamento. Pensamento esse que se faz pela força violenta de signos que exigem sua atividade de decifração, de entendimento. $\mathrm{O}$ signo é compreendido como aquilo que força o pensar do sujeito. Entendido como atividade, o pensamento não mais é concebido como representação de algo que lhe é exterior, mas 
como atividade que organiza de forma diferente o que lhe chega com os signos. O signo, então, tem o "poder" de provocar novos rearranjos, promovendo efeitos, gerando invenção a partir da multiplicidade.

$\mathrm{O}$ ato de problematizar, enfim, constitui-se a partir de signos que movem o pensamento, que são emitidos pelas múltiplas relações interativas e cooperativas e, no caso da EAD, atravessadas pelas tecnologias. Conforme Gallo (2008, p. 119):

O problema nos move a pensar justamente por que não somos capazes de compreendê-lo de antemão; ele não nos oferece uma resposta pronta, mas apresenta-se para nós como um desafio a ser enfrentado, para o qual uma resposta precisa ser construída. Todo o problema é uma multiplicidade, na medida em que é composto por um conjunto de singularidades.

Nesse entendimento, o problema se constitui a partir de encontros com os signos que capturam e incitam pensar e, a partir disso, saídas e possíveis soluções podem ser construídas. Os encontros possibilitam o pensamento e a aprendizagem, entendendo-se com Deleuze que:

Um encontro é talvez a mesma coisa que um devir ou núpcias. [...] Encontram-se pessoas (e às vezes sem as conhecer nem jamais tê-las visto), mas também movimentos, ideias, acontecimentos, entidades. Todas essas coisas têm nomes próprios, mas nome próprio não designa de modo algum uma pessoa ou sujeito. Ele designa um efeito, um ziguezague, algo que passa ou que se passa entre dois como sob uma diferença de potencial (DELEUZE; PARNET, 1998, p. 14).

No ambiente de EAD, as potencialidades para encontros se multiplicam. O professor, como disparador de signos (produtores de efeitos), aciona zonas de afetação que promovem pensamento. Essas, ao povoar o ambiente virtual, incitam expressões dos demais atores sociais (alunos, tutores, professores) que reverberam e explodem em outras tantas zonas de impacto para produção do conhecimento. $\mathrm{O}$ professor pode viabilizar possibilidade de encontros com algo (filme, obra de arte, música, texto, autor, situações do contexto presente, literatura), alguém que incita a 
pensar, a entender, a elaborar e que pode engatar e mobilizar para o pensamento. $\mathrm{Na}$ construção dos planos da unidade de estudos, os professores propõem atividades provocadoras, disparadoras, capazes de mobilizar formas de pensar que possibilitem a problematização da realidade. $\mathrm{O}$ professor, nesse caso, pensa constantemente espaços para a promoção de encontros em um ambiente virtual e produz com os acadêmicos um conjunto de possibilidades para responder aos problemas suscitados.

No entanto, as soluções dependerão da atribuição de sentido ao problema, uma vez que se não houver atribuição de sentido ao que está sendo proposto, nem mesmo a problematização da realidade ocorre. De outro modo, pode-se dizer que a compreensão e solução de um problema dependem de como se agenciam as singularidades que o compõem e que resultam em diferentes modos de soluções e aprendizagens.

Disso decorre que as possíveis soluçôes desencadeiamse nos encontros e vizinhanças (DELEUZE, 1988) ou em redes de conversações, que segundo Maturana (2003), atuam como transformações em um meio particular de interaçôes recorrentes, nas quais o outro se institui como um legitimo outro na convivência e na aprendizagem.

No contexto contemporâneo, o desafio posto à Educação a Distância está em potencializar novos modos de ensino e de aprendizagem, conjugados com os agenciamentos de novas formas de pensar, se subjetivar e criar conhecimento. Desse modo, é necessário considerar que a mesma subjetividade que produz tecnologias, em processos de objetivação de si, deixa-se, em seguida, subjetivar por ela, vivendo e aprendendo, conhecendo, segundo modos possíveis resultantes dessa relação (GUATTARI, 1996 apud AXT, 2003, p. 143). A tecnologia e a subjetividade fundem, agenciando singulares e característicos modos de pensar, de aprender, de conhecer, sendo essas novas relações que necessitam ser pensadas e aprimoradas nos processos de formação.

Os modos de conhecer e viver na contemporaneidade, atravessados pelas TICs, instalam, para o ensino presencial e 
para o ensino a distância, a necessidade de ações interativas que visem à iniciativa, à flexibilidade e à autonomia no processo de formação, dimensões essas que expressam rupturas de cunho epistemológico e pedagógico aos modelos de ensino centrados no professor e na transmissão de conteúdos.

Romper com tal visão de ensino implica ter como princípio a constituição de um sistema de comunicação aberto que possibilite a formação através da construção coletiva e criativa de conhecimento. De acordo com Borges (2007, p. 1),

[...] fornecer subsídios para auxiliar no processo de ruptura da concepção tradicional de educação, que se fundamenta na transmissão de conteúdos, centrada na figura do professor, cujo tipo de comunicação predominante é a comunicação unidirecional, do tipo um-todos. Já na educação a distância, através das tecnologias digitais, temos a possibilidade de construir o modelo comunicacional todos-todos.

À medida que as relações de comunicação ocorrem na lógica todos-todos ou muitos-muitos, é relevante ressaltar que há, compondo o processo pedagógico, múltiplas e heterogêneas formas de ser, pensar e aprender. Nesse sentido, a realização de trabalhos pedagógicos e de desenho de cursos que se institui na heterogeneidade sugere que, " $[\ldots]$ a palavra heterogeneidade convém a um trabalho incessante, arriscado, aberto a uma aposta na diferença e na multiplicidade como sinal de alerta contra a totalidade e o totalitarismo" (VIDAL, 2000, p. 479).

Para que se desenvolvam aprendizagens nesse processo, é necessário que na ancoragem da operação pedagógica na EAD se promova autonomia, interatividade e cooperação. O exercício da autonomia se compõe pela implicação, responsabilidade com o outro e, consequentemente, com o que se produz por meio do ensino e das aprendizagens.

Nesta proposta de EAD, busca-se desenvolver o espírito crítico para que, por intermédio de uma postura problematizadora, o aluno possa tornar-se sujeito de sua aprendizagem, incitando, assim, o desenvolvimento da autonomia. Entende-se que autonomia significa ser autor da própria fala e do próprio agir, 
assumindo-se como protagonista na integração do conhecimento com a ação. De tal modo, o processo de formação proposto busca a abertura para debates, diálogos, encontros e experimentações de novos modos de estar no mundo, promovendo resistências aos modos de ser que impedem a potência do pensamento e da vida.

Para tanto, é preciso buscar a formação que conecte forças heterogêneas e múltiplas, o que significa romper com modos de ensino fundamentados em verdades absolutas e imutáveis, previsibilidade das subjetividades e transmissão de conteúdos desvinculados do mundo da vida. Ao contrário, pautando-se pelo entendimento de que o ensino ocorre em um campo aberto de possibilidades para construções, desconstruções, criações e riscos como experiências para a constituição da autonomia e da criação de conhecimento, é que se organiza a Educação a Distância da CNEC.

No entanto, para que ocorra efetiva interação professoraluno, aluno-aluno, enfim, entre os atores do processo de construção coletiva do conhecimento, é necessário promover a interatividade e a cooperação.

A interatividade é uma dimensão que se potencializa pelas vias de comunicação, e está na disposição ou predisposição para interação, participação e intervenção dos atores. A interatividade, desejada em qualquer processo educativo, requer movimento dos atores, pois no momento em que se dispóem a exporem-se no grupo, seja propondo uma questão, um problema, uma ideia, se abrem uma variedade de zonas de acionamento de novas questôes inusitadas aos demais atores. Esse acionamento pode ser gerador de outras aprendizagens não previstas e variadas. Ainda que o movimento que a impulsione possa não ser cooperativo, a ação advinda dele pode ser. Ou seja, instaurar interatividade implica tensionamento propício à cooperação, entendida como esforço empreendido por um agrupamento de pessoas tendo em vista alcançar objetivos relacionados a um propósito em comum (PERNIGOTTI, 2004). 
É ainda pressuposto da ação educativa proposta pelo $\mathrm{CEAD} / \mathrm{CNEC}$ a hipertextualidade. Esse conceito é associado ao de rizoma de Deleuze e Guattari (1995). A hipertextualidade, nesse contexto, se refere tanto às características do suporte tecnológico como também a uma posição pedagógica que permite e incita a construção do conhecimento por vários caminhos. A utilização da potência da rede www na construção do material didático e a abertura para várias trajetórias na construção de conceitos que caracterizam a proposta de EAD da CNEC.

\section{Modos de existir em EAD}

Pode-se dizer que os diferentes modos de existir em EAD, signos propagados no início deste texto, foram a afetação, o acolhimento e a problematização, tendo como perspectiva a construção coletiva por meio de encontros. Para tanto, é preciso considerar as diferentes perspectivas teóricas e modos de vida dos que atuam na construção da EAD CNEC e, a partir disso, procurar

[...] destacar sempre um acontecimento das coisas e dos seres, [...]. Erigir o novo evento das coisas e dos seres, dar-lhes sempre um novo acontecimento: o espaço, o tempo, a matéria, o pensamento, o possível enquanto acontecimentos" (DELEUZE; GUATTARI, 1995, p. 46).

Tais acontecimentos são possíveis a partir da disponibilidade subjetiva de se deixar afetar pelas situações que produzem rupturas aos modos de vida cotidianamente repetitivos e tornarse outro. Esse entendimento implica apostar que as situações de diferença que nos afetam podem subverter a realidade e provocar a invenção de novos mundos, novos modos de ser e pensar para além do reino do controle, da cristalização do conhecido que nos sufoca, diria-nos o filósofo Gilles Deleuze.

A pergunta "De que afetos você é capaz?" foi fundamental na constituição da proposta educativa e da equipe multidisciplinar do CEAD CNEC. Conforme Benetti (2007), essa questão Deleuze retoma do filósofo Spinoza para salientar que os afetos 
nos tornam mais fortes quando aumentam a nossa potência para agir e para construir relações alegres e nos tornam mais fracos quando diminuem nossa capacidade para agir e para nos relacionar. Mas, quando há um bom encontro, que pode ser com uma pessoa, um livro, um filme, enfim, quando nos encontramos com algo que nos afeta e potencializa nossa capacidade de agir, estamos vivenciando o acontecimento que subverte a lógica do mesmo. Portanto, estamos subvertendo e, com isso, afetando outras pessoas e modos de viver. Estamos propagando afetos alegres que possibilitam a criação de novos modos de vida. Diz Deleuze (1998, p. 73), retomando Spinoza, que:

Todos os indivíduos estão na Natureza como sobre um plano de consistência cuja figura inteira eles formam, variável a cada momento. Eles se afetam uns aos outros, à medida que a relação que constitui cada um forma um grau de potência, um poder de ser afetado. Tudo é apenas encontro no Universo, bom ou mau encontro.

Assim, torna-se importante questionar se a sociedade em que vivemos e a formação que estamos propondo, na modalidade EAD ou presencial, impulsionam capacidades de agir e de produzir relações alegres ou convocam afetos tristes. Para Deleuze, "[...] vivemos em um mundo desagradável, onde não apenas as pessoas, mas os poderes estabelecidos têm interesse em nos comunicar afetos tristes" (1998, p. 73). No entanto, podemos propagar afetos alegres que potencializem a vida em suas diferenças, movimentos e incertezas.

\section{O que se pode pensar?}

A construção do espaço-tempo da EAD da CNEC se ancora num modo de existir que pauta a ação da equipe multidisciplinar. A vivência constituída por uma profunda interlocução busca revisitar constantemente os posicionamentos filosóficos e pedagógicos de seus membros, explicitar os fundamentos de suas ações e, em cooperação, criar modos para equacionar uma 
proposta de EAD. Essa preocupação se fez presente para assegurar que as escolhas efetivadas pudessem se refletir em todas as ações que se realizam cotidianamente quando se implanta uma operação pedagógica.

Resta afirmar que um processo como esse cria espaços para ampliar a aliança dos partícipes com o projeto, permite que se obtenha mais consistência entre pensamento e gesto, amplia a autonomia dos sujeitos, que uma vez compreendendo as premissas que orientam as ações, podem articular e tomar decisões no nível dos cursos em consonância com o que se almeja alcançar.

\section{Referências}

ABBAGnANO, Nicola. Dicionário de Filosofia. São Paulo: Mestre Jou, 1982.

AXT, Margarete. Educação (a distância): apontamentos para pensar modos de habitar a sala de aula In: Interface - Comunicação, Saúde, Educação, v. 7, n. 12, fev. 2003, p. 139-48.

BADIOU, Alain. Ética: um ensaio sobre a consciência do Mal. Rio de Janeiro: Relume - Dumará,1995.

BENETTI, Cláudia Cisiane. Estilos singulares de ser e de viver que constituem as entranhas de uma cidade. In: SAENGER, Liane; VARGAS GIL, Carmen Zeli de (Orgs.). Gentes de Osório: vivências inspiradoras. Porto Alegre: Pallotti, 2007.

BORGES, Martha Kaschny. Educação a distância: o que pensam os estudantes dos cursos de pedagogia?, ANPED, 2007. Disponível em: http:// www.anped.org.br/reunioes/30ra/trabalhos/GT16-3134--Int.pdf. Acesso em: 05 nov. 2010.

CARBONARA, Vanderlei. Docência e Ética: um apelo humano por uma Pedagogia da Justiça. In: KUIAVA, Evaldo Antônio; SANGALLI, Idalgo José; CARBONARA, Vanderlei. (Orgs.). Filosofia, formação docente e cidadania. Ijuí: Ed. Unijuí, 2008, p. 127-142.

CENCI, Angelo Vitório; DALBOSCO, Cláudio Almir; FÁVERO, Altair Alberto. A formação cultural como exigência para a formação docente: 
aproximações filosóficos educativas de Adorno. In: KUIAVA, Evaldo Antônio; SANGALLI, Idalgo José; CARBONARA, Vanderlei. (Orgs.). Filosofia, formação docente e cidadania. Ijuí: Ed. Unijuí, 2008, p. 107126.

DELEUZE, Gilles. Diferença e repetição. Rio de Janeiro: Graal, 1988.

DELEUZE, Gilles; PARNET, Claire. Diálogos. São Paulo: Escuta, 1998. DELEUZE, Gilles; GUATTARI, Félix. Mil Platôs. Capitalismo e Esquizofrenia. Rio de Janeiro: Ed. 34, 1995

FOUCAULT, Michel. Dits e écrits. Paris: Gallimart, 1994.

GALLO, Silvio. O problema e a experiência do pensamento: implicações para o ensino da filosofia. In: BORBA, Siomara; KOHAN, Walter (Orgs.). Filosofia, Aprendizagem, Experiência. Belo Horizonte: Autêntica, 2008, v. 1 , p. $115-130$

MATURANA, Humberto. A ontologia da realidade. Belo Horizonte: UFMG, 2003.

MARCONDES, Danilo. Textos básicos de ética: de Platão a Foucault. Rio de Janeiro: Zahar, 2007.

NIETZSCHE, Friedrich. Vontade de Potência. Porto Alegre: Globo, 1945.

PERNIGOTTI, Joyce Munarski. Um povoamento em EAD: tensões e torções em operação. Tese (Doutorado) - Pontifícia Universidade Católica do Rio Grande do Sul. Programa de Pós-Graduação em Psicologia da PUCRS, 2004.

VIDAL, Eduardo. Heterogeneidade Deleuze-Lacan. In: ALLIEZ, Eric (Org.). Gilles Deleuze: uma vida filosófica. São Paulo: Editora 34, 2000. 